\title{
Conseqüência da umidade relativa durante o armazenamento refrigerado e em atmosfera controlada na qualidade da maçã 'Gala'
}

\author{
Consequence of the relative humidity during the cold storage and controlled \\ atmosphere in the quality of 'Gala' apple
}

\author{
Auri Brackmann ${ }^{2}$ Josuel Alfredo Vilela Pinto ${ }^{3}$ Cristiano André Steffens $^{4}$

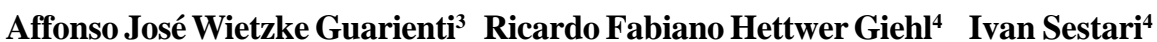

\section{- NOTA -}

RESUMO

O objetivo do presente trabalho foi avaliar o efeito da umidade relativa no armazenamento refrigerado e em atmosfera controlada sobre a qualidade de maçãs 'Gala' colhidas tardiamente. Os tratamentos foram armazenamento refrigerado + alta umidade relativa (96\%), armazenamento refrigerado + baixa umidade relativa (90\%), atmosfera controlada + alta umidade relativa (96\%) e atmosfera controlada + baixa umidade relativa (90\%). Os frutos de todos os tratamentos foram mantidos a $0,5^{\circ} \mathrm{C}$ e a condição de atmosfera controlada foi de $1,2 \mathrm{kPa} \mathrm{O}_{2}+$ 3,0kPa $\mathrm{CO}_{2}$. Após sete meses de armazenamento, os frutos mantidos sob baixa umidade relativa (90\%) apresentaram menor incidência de rachaduras, porém maior índice de murchamento na retirada da câmara. Após cinco dias de exposição a $20^{\circ} \mathrm{C}$, os frutos mantidos em baixa umidade relativa, tanto em armazenamento refrigerado quanto em atmosfera controlada, apresentaram menor incidência de podridão e rachaduras. A incidência de degenerescência da polpa e polpa farinácea não foi influenciada pela umidade relativa.

Palavras chave: Malus domestica, pós-colheita, qualidade.

\begin{abstract}
The objective was to evaluate the effect of relative humidity in cold and controlled atmosphere storage on the quality of 'Gala' apples. The evaluated treatments were: cold storage + high humidity (96\%), cold storage + low humidity (90\%), controlled atmosphere + high humidity (96\%), controlled atmosphere + low humidity $(90 \%)$. Fruit of all treatments were stored at $0.5^{\circ} \mathrm{C}$ and the controlled atmosphere conditions was $1.2 \mathrm{kPaO} \mathrm{O}_{2}+3.0 \mathrm{kPaCO}$. After seven months, fruit stored in low humidity had smaller incidence of fruit cracking, but higher shriveling index. After five days at $20^{\circ} \mathrm{C}$, fruit maintained in cold storage and in controlled atmosphere with low humidity, showed lower decay incidence and less fruit cracking. Flesh breakdown and mealiness was not influenced by relative humidity in storage room.
\end{abstract}

Key words: Malus domestica, postharvest, quality.

O armazenamento refrigerado, que consiste apenas no controle da temperatura e da umidade

\footnotetext{
${ }^{1}$ Pinto, bolsista da Fundação de Amparo à Pesquisa do Estado do Rio Grande do Sul. Steffens, Giehl e Sestari, bolsistas da Coodernação de Aperfeiçoamento de Pessoal de Nível Superior. Guarienti, bolsista do Conselho Nacional de Desenvolvimento Científico e Tecnológico.

${ }^{2}$ Departamento de Fitotecnia, Universidade Federal de Santa Maria (UFSM), 97105-900, Santa Maria, RS, Brasil. E-mail: brackman@ccr.ufsm.br. Autor para correspondência.

${ }^{3}$ Curso de Agronomia, UFSM, Santa Maira, RS, Brasil.

${ }^{4}$ Programa de Pós-graduação em Agronomia, UFSM, Santa Maira, RS, Brasil.
} 
relativa, é a forma mais utilizada pelas empresas produtoras e/ou comercializadoras de maçã. Este sistema permite um curto período de conservação, devido ao rápido amadurecimento e à incidência de podridões, principalmente quando se tem alta umidade relativa. O armazenamento em atmosfera controlada, que consiste na redução da concentração de $\mathrm{O}_{2}$ e aumento na do $\mathrm{CO}_{2}$, é uma tecnologia de maior custo, mas sua utilização vem aumentando a cada ano, por apresentar a vantagem de uma maior redução na taxa respiratória e retardo na maturação. No entanto, mesmo em condições de atmosfera controlada, a maçã 'Gala' é muito suscetível a perdas, devido a ocorrências de podridões e distúrbios fisiológicos, como degenerescência senescente, polpa farinácea e rachaduras, principalmente em frutos colhidos tardiamente.

O estabelecimento de alta umidade relativa dentro das câmaras, durante o armazenamento, é importante para evitar a desidratação e preservar a qualidade dos frutos. Esta umidade não deve permanecer muito baixa, pois, além da maior perda de peso, causa murchamento e perdas nutricionais (KADER, 1986). Entretanto, a alta umidade relativa do ar pode predispor à ocorrência de degenerescência senescente (LITTLE \& BARRAND, 1989) e ao desenvolvimento de infecções por fungos patogênicos (SCHWARZ, 1994). A incidência de degenerescência da polpa em frutos da cultivar McIntosh é maior com a umidade relativa entre $96 \%$ e 100\% (LIDSTER, 1990), assim como o surgimento de rachaduras na epiderme (EBERT, 1984). BORTOLUZZI et al. (1995) observaram em maçã 'Fuji' maior incidência de degenerescência senescente com umidade relativa a $97 \%$ em comparação com $92 \%$ de umidade relativa.

O objetivo do presente trabalho foi avaliar o efeito da umidade relativa, no armazenamento refrigerado e sob atmosfera controlada sobre a qualidade de maçãs 'Gala’ colhidas tardiamente.

O experimento foi realizado em 2003, no Núcleo de Pesquisa em Pós-colheita do Departamento de Fitotecnia da Universidade Federal de Santa Maria com maçãs 'Gala', colhidas em 23 de março do ano agrícola 2002-2003, provenientes da empresa Agropecuária Schio de Vacaria, RS. Após o transporte dos frutos a Santa Maria, procedeu-se à seleção e à homogeneização das amostras experimentais. Os frutos foram armazenados durante sete meses em minicâmaras experimentais com volume de $0,232 \mathrm{~m}^{3}$.

O delineamento experimental utilizado foi o inteiramente casualizado com cinco repetições de 30 frutos. Os tratamentos avaliados foram: armazenamento refrigerado + alta umidade relativa (96\%), armazenamento refrigerado + baixa umidade relativa (90\%), atmosfera controlada + alta umidade relativa (96\%), atmosfera controlada + baixa umidade relativa (90\%). Todos os tratamentos foram mantidos a $0,5^{\circ} \mathrm{C}$, e nos tratamentos sob atmosfera controlada utilizou-se as pressões parciais de $1,2 \mathrm{kPa} \mathrm{O}_{2}+3,0 \mathrm{kPa} \mathrm{CO}_{2}$.

Para manter a umidade relativa em 90\%, colocaram-se $200 \mathrm{~g}$ de cloreto de cálcio nas minicâmaras, com monitoramento através de psicrômetros, instalados no interior destas minicâmaras. A pressão parcial inicial de $\mathrm{O}_{2}$ nos tratamentos em atmosfera controlada foi obtida pelo princípio de diluição com a varredura do $\mathrm{O}_{2}$ através da injeção do gás nitrogênio, proveniente de um gerador que utiliza o sistema "Pressure Swing Adsorption" (PSA), até a obtenção da pressão parcial préestabelecida. A pressão parcial de $\mathrm{CO}_{2}$ nas minicâmaras foi obtida através da injeção deste gás, proveniente de um cilindro de alta pressão.

Para a manutenção dos níveis de $\mathrm{O}_{2}$ e $\mathrm{CO}_{2}$, que se modificavam em função da respiração dos frutos, foram realizadas diariamente análises e correções das pressões parciais dos gases, com o auxílio do sistema automático de controle de gases da marca Kronenberger-Climasul. Assim, para repor o $\mathrm{O}_{2}$ consumido na respiração dos frutos, injetou-se ar atmosférico nas minicâmaras e o $\mathrm{CO}_{2}$, produzido pela respiração, foi absorvido por uma solução de hidróxido de potássio (40\%), pela qual circulava o ar das minicâmaras.

A temperatura de armazenamento foi regulada por um termostato de alta precisão, sendo, monitorada durante todo o período de armazenamento, por termômetros com bulbo de mercúrio introduzidos na polpa de frutos, havendo uma oscilação de $\pm 0,2^{\circ} \mathrm{C}$.

As avaliações foram realizadas após sete meses de armazenamento e após cinco dias de exposição dos frutos à temperatura de $20^{\circ} \mathrm{C}$, simulando o tempo necessário para o transporte e/ou comercialização dos frutos. Avaliou-se, na saída da câmara, as seguintes variáveis dependentes: podridão, rachadura e índice de murchamento e após cinco dias de exposição a $20^{\circ} \mathrm{C}$ avaliou-se a presença de degenerescência senescente, polpa farinácea, podridões, rachaduras, acidez titulável, sólidos solúveis totais (SST), firmeza de polpa e cor de fundo da epiderme. Para o índice de murchamento, considerou-se: nível 1 = sem sinal de murchamento sob pressão dos dedos; 2 = sinal de murchamento sob leve pressão dos dedos; 3 = sinal de murchamento sem realizar pressão com os dedos. O índice de cada unidade experimental foi obtido multiplicando-se o número de frutos pelo nível constatado, que foi dividido pelo número total de frutos. Já para a avaliação dos 
parâmetros degenerescência senescente, polpa farinácea, podridões, rachaduras, acidez titulável, sólidos solúveis totais (SST), firmeza de polpa e cor de fundo da epiderme seguiu-se a metodologia descrita em BRACKMANN \& SAQUET (1995). Os valores das variáveis podridão, rachadura, degenerescência senescente e polpa farinhenta, expressos em porcentagem, foram transformados pela fórmula $\operatorname{arc.sen} \sqrt{\mathrm{x} / 100}$ antes da análise da variância. As médias foram comparadas pelo teste de Duncan a 5\% de probabilidade de erro.

Na saída da câmara, não foi observada diferença estatística entre os tratamentos para podridão (Tabela 1). Após cinco dias de exposição a $20^{\circ} \mathrm{C}$, os frutos em baixa umidade relativa (90\%) apresentaram menor incidência de podridão em relação aos armazenados em alta umidade relativa (Tabela 2), confirmando que umidade relativa próximo a $100 \%$ promove maior desenvolvimento de podridão (SCHWARZ, 1994).

A rachadura de frutos, tanto na saída da câmara como após cinco dias de exposição a $20^{\circ} \mathrm{C}$, foi maior nos tratamentos com alta umidade relativa (Tabelas 1 e 2). A incidência de rachaduras em maçãs armazenadas em alta umidade relativa é conseqüência do aumento do volume dos frutos (SCHWARZ, 1994), bem do como amadurecimento avançado dos frutos (BRACKMANN \& SAQUET, 1995).

A ocorrência de degenerescência senescente e polpa farinácea, após cinco dias de exposição a $20^{\circ} \mathrm{C}$, foi menor em atmosfera controlada, sendo que em todos os tratamentos não se observaram efeito das umidades relativas sobre estas variáveis (Tabela 2). A ocorrência destes distúrbios fisiológicos foram maiores nos frutos armazenados somente sob refrigeração, provavelmente, devido à avançada maturação que os frutos apresentavam após o armazenamento.

As características físico-químicas acidez titulável, sólidos solúveis totais (SST) e firmeza de polpa não foram influenciadas pela variação na umidade relativa (Tabela 3). A baixa umidade relativa no armazenamento sob atmosfera controlada levou a um maior amarelecimento e murchamento dos frutos em relação à alta umidade relativa (Tabela 3). Provavelmente a desidratação da epiderme dos frutos tenha ativado as enzimas responsáveis pela degradação das clorofilas. No armazenamento refrigerado, não houve diferença porque, tanto em baixa como em alta umidade relativa, os frutos estavam intensamente amarelos.

Tabela 1 - Ocorrência de podridão, rachaduras e murchamento em maçãs 'Gala’ após sete meses de armazenamento a $0,5^{\circ} \mathrm{C}$. Santa MariaRS, 2005.

\begin{tabular}{lccc}
\hline Condição de armazenamento & Podridão (\%) & Rachadura (\%) & Índice de murchamento (1-3) \\
\hline Armazenamento Refrigerado + 96\% Umidade relativa & $9,90 \mathrm{a}^{*}$ & $4,00 \mathrm{a}$ & $1,00 \mathrm{c}$ \\
Armazenamento Refrigerado + 90\% Umidade relativa & $2,50 \mathrm{a}$ & $0,50 \mathrm{~b}$ & $1,58 \mathrm{~b}$ \\
Atmosfera Controlada + 96\% Umidade relativa & $6,67 \mathrm{a}$ & $4,25 \mathrm{a}$ & $1,00 \mathrm{c}$ \\
Atmosfera Controlada + 90\% Umidade relativa & $3,33 \mathrm{a}$ & $0,00 \mathrm{~b}$ & $2,08 \mathrm{a}$ \\
Coeficiente de variação (\%) & 47,24 & 24,17 & 36,40 \\
\hline
\end{tabular}

*Tratamentos com médias seguidas pelas mesmas letras não diferem estatisticamente entre si pelo teste de Duncan a 5\% de probabilidade de erro.

Tabela 2 - Ocorrência de degenerescência senescente, polpa farinhenta, podridão e rachadura em maçãs 'Gala' após sete meses de armazenamento a $0,5^{\circ} \mathrm{C}$ mais cinco dias à temperatura de $20^{\circ} \mathrm{C}$. Santa Maria-RS, 2005.

\begin{tabular}{|c|c|c|c|c|}
\hline Condição de armazenamento & $\begin{array}{l}\text { Degenerescência senescente } \\
\qquad \text { (\%) }\end{array}$ & $\begin{array}{l}\text { Polpa farinhenta } \\
\qquad(\%)\end{array}$ & $\begin{array}{l}\text { Podridão } \\
\qquad(\%)\end{array}$ & $\begin{array}{c}\text { Rachadura } \\
\text { (\%) }\end{array}$ \\
\hline Armazenamento Refrigerado + 96\% Umidade relativa & $51,40 a^{*}$ & 66,9 a & $49,1 \mathrm{a}$ & $11,0 \mathrm{a}$ \\
\hline Armazenamento Refrigerado $+90 \%$ Umidade relativa & 56,9 a & 75,4 a & $7,2 \mathrm{c}$ & $0,0 \mathrm{~b}$ \\
\hline Atmosfera Controlada + 96\% Umidade relativa & $6,6 \mathrm{~b}$ & $34,8 \mathrm{~b}$ & $26,2 \mathrm{~b}$ & 9,1 a \\
\hline Atmosfera Controlada $+90 \%$ Umidade relativa & $9,0 \mathrm{~b}$ & $19,2 \mathrm{~b}$ & 7,9 c & $0,0 \mathrm{~b}$ \\
\hline Coeficiente de variação (\%) & 22,61 & 21,77 & 31,10 & 34,39 \\
\hline
\end{tabular}

*Tratamentos com médias seguidas pelas mesmas letras não diferem estatisticamente entre si pelo teste de Duncan a 5\% de probabilidade de erro.

Ciência Rural, v.35 n. 5, set-out, 2005. 
Tabela 3 - Firmeza de polpa, sólidos solúveis totais (SST), acidez titulável e cor de fundo em maçãs 'Gala' após sete meses de armazenamento a $0,5^{\circ} \mathrm{C}$ mais cinco dias à temperatura de $20^{\circ} \mathrm{C}$. Santa Maria-RS, 2005.

\begin{tabular}{|c|c|c|c|c|}
\hline Condição de armazenamento & $\begin{array}{l}\text { Firmeza de polpa } \\
\text { (N) }\end{array}$ & $\begin{array}{c}\text { SST } \\
\text { ( }{ }^{\circ} \text { Brix) }\end{array}$ & $\begin{array}{l}\text { Acidez titulável } \\
\left(\text { meq } 100 \mathrm{ml}^{-1} \text { ) }\right.\end{array}$ & $\begin{array}{l}\text { Cor de fundo } \\
(\text { CIE L*a*b*) }\end{array}$ \\
\hline Armazenamento Refrigerado + 96\% Umidade relativa & 40,6 b & $11,7 \quad b$ & $2,26 b^{*}$ & $59,2 \mathrm{a}$ \\
\hline Armazenamento Refrigerado $+90 \%$ Umidade relativa & $41,8 \mathrm{~b}$ & $12,4 \mathrm{ab}$ & $2,52 \mathrm{~b}$ & 59,9 a \\
\hline Atmosfera Controlada + 96\% Umidade relativa & 50,9 a & 12,6 a & 4,33 a & $47,6 \quad \mathrm{c}$ \\
\hline Atmosfera Controlada $+90 \%$ Umidade relativa & 53,4 a & 12,7 a & 4,57 a & 55,2 b \\
\hline Coeficiente de variação (\%) & 7,66 & 3,84 & 7,05 & 3,73 \\
\hline
\end{tabular}

*Tratamentos com médias seguidas pelas mesmas letras não diferem estatisticamente entre si pelo teste de Duncan em 5\% de probabilidade de erro.

Em maçãs 'Gala’ pode-se observar que: a utilização de baixa umidade relativa no armazenamento refrigerado e atmosfera controlada é eficiente na redução de podridão e de rachadura da polpa, contudo causa desidratação e amarelecimento dos frutos. A umidade relativa não afeta a ocorrência de degenerescência senescente, firmeza de polpa, acidez e sólidos solúveis totais no armazenamento refrigerado e em atmosfera controlada.

\section{REFERÊNCIAS}

BORTOLUZZI, G. et al. Armazenamento de maçãs 'Fuji' em diferentes temperaturas e concentrações de $\mathrm{CO}_{2}$ e $\mathrm{O}_{2}$. In: JORNADA INTEGRADA DE PESQUISA, EXTENSẪO E ENSINO, 2., 1995, Santa Maria. Anais... Santa Maria: UFSM, 1995. p.380.

BRACKMAN, A.A.; SAQUET, A.A. Armazenamento de maçã cv. Gala em atmosfera controlada. Revista Brasileira de Agrociência, Pelotas, v.1, n.2, p.55-60, 1995.
EBERT, A. Distúrbios fisiológicas. In: EMPASC (ed.). Palestras do II Curso Sobre a Cultura da Macieira. Caçador : EMPASC, 1984. p. 129-134.

KADER, A.A. Biochemical and physiological basis for effects of controlled and modified atmospheres on fruits and vegetables. Food Technology, Chicago, v.40, n.5, p.99-104, 1986.

LIDSTER, P. D. Storage humidity influences fruit quality and permeability to ethane in 'McIntosh' apples stored in diverse controlled atmospheres. Journal American Society for Horticulture Science, Alexandria, v.114, n.1, p.94-96, 1990.

LITTLE, C. R., BARRAND, L. The effect of preharvest, postharvest and storage conditions on some fruits disorders. In: INTERNATIONAL CONTROLLED ATMOSPHERE RESEARCH CONFERENCE, 5, Washington, 1989. Proceedings... Washington: Washington State University, 1989. v.1, 515p. p. 185-192.

SCHWARZ, A. Relative humidity in cool stores: measurement, control and influence of discreet factors. Acta Horticulturae, Wageningen, v.2, n.368, p.687-692, 1994. 